Makale Geliș | Received: 26.01.2021

Mavi Atlas, 9(1)2021: 147-170

Makale Kabul | Accepted: 07.04.2021

DOI: $10.18795 /$ gumusmaviatlas. 868808

Araştırma Makalesi | Research Article

Gülser YARDIM

Doç. Dr. | Assoc. Prof. Dr. Nevşehir Hac1 Bektaș Veli Üniversitesi, Fen Edebiyat Fakültesi, Tarih Bölümü, Nevșehir-TÜRKIYYE Nevşehir Hac1 Bektaş Veli University, Faculty of Science and Literature, The History Department

Nevşehir-TURKEY

ORCID: 0000-0003-3338-5982

gulseroguz@nevsehir.edu.tr

\title{
17. Yüzyılın İkinci Yarısına Ait Bir Deftere Göre Muhallefattan Hazineye Aktarılan Eşyalar
}

$\ddot{O} z$

Bu çalışma için Devlet Arşivleri Başkanlığı Osmanlı Arşivi’nden temin edilen Fon TS.MA.d. kutu/gömlek no 02321.0001.00 künyeli defter kullanılacaktır. Defter yaklaşık 60 sayfadır. Defterin mikrofilm görüntüsü iki sayfa tek bi görüntüye gelecek şekilde a ve b yüzlü olarak kaydedilmiştir. Bu çalışma için defterin yarısı kullanılacaktır. Defter incelendiğinde yarıya kadar olan sayfalarının muhallefatlardan gelen eșyalar olduğu anlaşılmaktadır. Muhallefat, ölen kişinin geride kalan mal varlığını ifade eden bir terimdir. Dolayısıyla defter 1665'li yıllara ait Osmanlı Devleti'ndeki maddi kültür unsurlarına dair pek çok veriyi sağlamaktadır. Bu çalışmadaki amaç defterin birebir çevirisini yaparak giyimden mutfak eşyalarına, silahtan at koşum aletlerine kadar çok geniş bir yelpazede kaydedilen verileri ortaya çıkarmaktır. Bu eşyaların sepetler ve sandıklar içine konulup hazineye aktarılmasıyla ortaya çıkan defteri birebir çevirerek alana katkı yapmayı planlamaktayız. Defter üzerinde yapılan çalışmada her bir eşyanın cinsi net bir şekilde belirtildikten sonra adedi mutlaka kaydedildiği görülmüştür. Eşyaların fiyat olarak değeri verilmemiştir. Bu sebeple hazineye aktarılan bu malların parasal değeriyle ilgili yorum yapmamız mümkün olmamaktadır. Yine de bu veriler bu eksiliğine karşın değerini korumaktadır. Çünkü dönemin kullanılan eşyaları, kumaş çeşitleri, silah çeşitleri, kumaş türleri, kap kacaklar, at takımları ve hayatın geri kalanına dair pek çok konuda kıymetli veriler sağlamaktadır. Bu veriler bize Osmanlı piyasasındaki kullanılan eșyaların nerelerden geldiği, nelerden üretildiği ve çeșitleriyle ilgili bilgi sağlamaktadır.

Anahtar Kelimeler: Hazine-i Amire, Enderûn Hazinesi, Muhallefât, 17. yüzyıl.

\section{Goods Transferred From Muhallefat to the Treasury According to a Notebook From the Second Half of the $17^{\text {th }}$ Centrury}

\begin{abstract}
For this study, a notebook with the tag of Fund TS.MA.d. box / cover no 02321.0001.00 obtained from the Ottoman Archives of the Directorate of State Archives will be used. The notebook consists of about 60 pages. The microfilm image of the notebook was recorded as two pages on a single image, with sides of a and b. Half of the notebook will be used for this study. When the notebook is examined, it is understood that the half of its pages inculude goods from muhallefat. Muhallefat is a term that refers to the assets left behind by the deceased. Therefore, the notebook provides a lot of data on the material culture elements in the Ottoman Empire in the 1665s. The aim of this study is to reveal a wide range of recorded data, from clothing to kitchen utensils, from guns to horse harnesses, by translating the notebook literally. We plan to contribute to the field by translating the notebook created by putting these goods into baskets and chests and transferring them to the treasury. In the study conducted on the notebook, it was seen that the number of each item was recorded after the type of item was clearly stated. The price of the goods was not indicated. For this reason, it is not possible to comment on the monetary value of these goods transferred to the treasury. Nevertheless, the data preserves its value despite this deficiency because it provides valuable information on many subjects including the goods used in the period, fabric types, weapon types, fabric types, utensils, horse sets, and the rest of life. The data provides us with information about where the goods used in the Ottoman market came from, what they were produced from, and their types.
\end{abstract}

Keywords: Hazine-i Amire, Enderûn Hazinesi, pudding, $17^{\text {th }}$ Centrury. 


\section{Giriş}

Bu çalışma yaklaşık olarak 1665 yllına gelen dönemdeki hazine ye aktarılan malların kaydını tutan bir defterin kaynaklığında yapılacaktır. Çalışmanın aslını bu defterin transkripsiyonu ve değerlendirilmesi oluşturacaktır. Ancak öncelikle defter tanıtılacak ve sonrasında hazine ile ilgili kısa bir bilgi verilecektir.

\section{Defterin Tanıtılmas1}

Çalışmaya kaynaklık eden defter, Devlet Arşivleri Başkanlığ Osmanlı Arşivi'nden temin edilmiştir. Defterin künyesi Fon TS.MA.d. kutu/gömlek no 02321.0001 .00 şeklindedir. Deftere ait 34 adet mikrofilm görüntüsü mevcuttur. Defterin 1076 (1665) senesine ait olduğu tespit edilmiştir. Bu senenin Muharrem ayı ile başlayan defterin son sayfalarında 1076 Rebi'ül-evvel ayı kaydına rastlanmıştır (TS.MA.d.02321.0001.00 s. 2a, 32a.). 19 a sayfasında da yine 1076 senesine ait kayit mevcuttur (TS.MA.d.02321.0001.00 s. 19a). Bununla beraber defterin bazı sayfalarında daha önceki yıllara ait kayıtlara da rastlanmıștır. Mesela 31 a sayfasında 1072, 31b sayfasında 1073 senesine ait veriler bulunmaktadır (TS.MA.d.02321.0001.00 s. 31 a, b). 22 b sayfasinda da tarih olarak 1078 kaydı vardır (TS.MA.d.02321.0001.00 s. 22b). Dolayısıyla defterin tutulmasinda tarihsel süreçte bir dalgalanma söz konusudur. Defterin özellikle bazı sayfalarında tutulan kayıtların üzerinin kalemle karalandığ1 görülmüsstür. Bu durumun da göz önüne alarak bu defterin müsvedde bir defter mi olduğu akla gelmektedir. Fakat bu durum yani defterin karalama defteri olması durumu bizim çalışmamızı gölgeleyecek mahiyette değildir. Çünkü çalışmanın odak noktası genelinde Hazine-i Amire'ye çeşitli sebeplerle giren malların kaydının tutulduğu bu defter sayesinde o dönemin pek çok alanda kullanılan eşyaları hakkında fikir sahibi olabilmek olacaktır. Böylelikle kültür tarihi çalışmalarına katkı sağlanmayı amaçlıyoruz.

Defter incelendiğinde belirtilmesi gereken bir diğer nokta, defterin 17 a ve b sayfalarının olmaması ve sonraki sayfalarda defterin hazineye çeşitli kollardan gelen malların kaydına dair tutulan bir defter halini almasıdır. Defter, 17. sayfaya kadar muhallefattan gelen malların toplu kaydı şeklinde bir intibaa uyandırmaktadır. Bu sebeple adı geçen defteri iki ayrı çalışmada ele almaya karar verdik. Hem defterin içeriğinin dağınık olması hem de tümünün bir makalenin sınırlarını fazlaca aşacak olması sebebiyle böyle bir ayrıma gidilmiştir. Dolayısıyla bu çalışmada defterin ikinci ve on altıncı sayfaları arasınını kapsayan, muhallefattan geldiği kaydı düşülen kısımları kullanilacaktır.

Defterdeki ilk mikrofilm kaydı defterin kapağına dairdir. İkinci mikrofilm ise yine iç kapağ1 göstermektedir. Çalışmamızı kaynaklık edecek veriler üçüncü mikrofilm ile başlamaktadır. Her mikrofilm görüntüsüne tek numara verildiği için biz de bu görüntüyü a ve b yüzü olarak künyeleyip defteri inceledik.

\section{Hazine}

Hazine kavramının kelime anlamı, para ve değerli eşyaların saklandığı yer, vezne, sandıktır (Parlatır, 2003: 610). Bu kavrama diğer İslam devletlerinde olduğu gibi Selçuklular'da da para, hil'at, vesika, silah, kıymetli eğer takımları ve mücevheratın saklandığı yer olarak hazine kelimesine sıkça rastlanır (Orhonlu, 1998: 130). Osmanlı Devlet teşkilâtına gelindiğinde de henüz kuruluş yıllarında kıymetli nakit ve malların korunduğu bir hazinenin var olduğu düşünülmektedir. Asıl olarak Osmanlı Devleti'nde hazine iç hazine ve dış hazine olmak üzere iki ana bölümden oluşmaktadır (Uzunçarşıl1, 1978: 73). Bu konudaki bir başka ifade şu şekildedir: Cengiz Orhonlu Osmanlılar'da XVIII. yüzyllın son çeyreğine kadar Enderûn (Hazîne-i Hâssa, iç hazine) ve Bîrun (maliye hazinesi, devlet hazinesi, dış hazine) adlarında iki hazinenin varlığına rastlanmakta, ancak bu ayrımın kesin olarak şekillendiği bilinmediğini belirtmektedir (Orhonlu, 1998: 130). Yalnız Fatih Sultan Mehmet'in (1451-1481) teşkilat kanunnamesinde, baş defterdarın 
bütün devlet mallarının nazırı durumunda olduğundan söz edilmesi ve yine burada "Ceyb Harçlığı" tabirine rastlanması bu ayırımın yavaş yavaş meydana geldiğini işaret etmektedir (Orhonlu, 1998: 130). Başka bir ifade ile XVIII. yüzyllın son çeyreğine kadar Osmanlıların, biri devlet gelirlerinin toplandığı ve masrafların yapıldığı dış hazine, Hazine-i Amire, Maliye Hazinesi, Divan-1 Hümâyûn Hazinesi, Birun Hazinesi, Taşra Hazinesi gibi adlarla anılan esas; diğeri, iç hazine, Enderûn Hazinesi olmak üzere iki hazinesi vardı.

Dış hazine devletin tahsil ettiği şeri ve örfi vergilerden meydana gelmiştir. Hazine, Divan-1 Hümâyûn toplantılarında açılır, toplantıdan sonra sadrazam tarafından mühr-ü Hümâyûn ile mühürlenirdi. Diş hazine, defterdarın sorumluluğu ve sadrazamın nezareti altındaydı (Mumcu, 1976:111; Tabakoğlu, 1996: 195).

Osmanlı Devleti'nde saray hazinesine, iç hazine ya da Enderûn Hazinesi denilmektedir. İç hazinenin gelirleri, dış hazineden artan fazla para, bazı haslar, cizye, adet-i ağnam, bazı mukataaların gelirleri, Mısır'dan gelen vergiler, çeşitli hediyeler, müsadere vesilesiyle ya da terekelerden aktarılan mallar, vakıf gelirleri ve çeşitli vergilerden oluşmakta idi (Köseoğlu, 1980: $4){ }^{1}$

Enderûn Hazinesi, kendi içinde çeşitli bölümlere ayrılmıştır. Bunlar Bodrum Hazinesi, İfraz Hazinesi, Çilhane, Hasoda, Raht (Has Ahur), Hil'at (Enderûn Dış Hazinesi) ve Ceyb-i Hümâyûn. (Harem-i Hümâyûn) idi (Uzunçarş1lı, 1978: 75).

Osmanlı hanedanından biri ölünce onun eşyalarının bir kısmının ya da tamamının Osmanlı Hazinesine aktarılması söz konusuydu (Sağır, 2016:265-328; Arg1t, 2014: 233; Akyıldız, 1998: 94; Oğuz, 2018:350 359). Bu eșyalar genellikle Enderûn Hazinesi’ne kaydedilirdi. ${ }^{2}$ Bunun dışında ölen bir askeri sınıf üyesinin müsadere ve başka sebeplerle mallarına el konulup bunlar hazineye aktarılabilirdi. Dolayısıyla muhallefattan geldiği belirtilen bu defterdeki eşyaların ve malların kimim olduğuna dair bilginin yer almadığını belirtmek gerekmektedir. ${ }^{3} \quad$ Yalnız belirtmek gerekir ki Hazine-i Amire denilen dış hazine ile Enderûn yani iç hazine birbirinden farklı yapilardır (Uzunçarşılı, 1988: 317). İç hazine daha çok padişahın gelir ve giderleri ile ilgilenmekteydi ve fonksiyon itibariyle kıymetli para, mücevher ve eşyaların saklandığ bir depo veya sandık vazifesini görmekteydi (Uzunçarlşıll, 1988: 317; Terzi, 2002: 893-903). Çalışmaya kaynaklık eden defterde aktarılan malların özellikle Enderûn Hazinesi’ne kaydedildiğine dair bir ibareye rastlanmamıştır. Birkaç yerde Hazine-i Amire ibaresine rastlanmıştır (TS.MA.d.02321.0001.00 s. 29a). Defterin başında şöyle bir açıklama yapıldığ1 görülmüştür:

\section{'Hüve'l-bâkî̀}

1076 senesi mâh-ı Mubarreminde muballefâtdan gelan esyalar yeniden defter olunub bu minvâl üzere sandiklara ve sepetlere vaz' olunmuşdur.' (TS.MA.d.02321.0001.00 s. 2a).

Bu cümleden hareketle hazineye kayt edilen bu malların hangi hazine olduğuna dair kesin bir yargıda bulunmak güç gibi görünmektedir. Ama muhallefattan gelen malların iç hazineye aktarıldığı bilgisi bizi o ihtimale yaklaştırmaktadır.

\footnotetext{
1 İç hazinenin harcamalarını gösteren örnek bir çalışma için bkz. Kadir Arslanboğa, Osmanl Devleti’nde İç Haz̧ine Harcamalar, (1649-1680), Ankara, 2014, Çanakkale Onsekiz Mart Üniversitesi Yayınları: 119. Bu çalışmada da Enderûn Hazinesi'nden yapılan harcamaların ne kadar geniş bir yelpazede olduğu gözler önüne serilmektedir. Bkz. Arslanboğa, 2014: 50-55. Enderun hazinesi gelirlerini gösteren bir inceleme için bkz. Yardım, 2019: 59.

${ }^{2}$ Hanedan mensuplarının ölümünden sonra mallarının bir kısmının Enderûn Hazinesine aktarılması bilindik bir uygulamadır. Önekler için bkz. Sağır, 2016: 265-328; İşpirli Argıt, 2014: 233. Hazine-i Hümâyûn'a aktarıldığı da vakidir. Bkz. Akyıldız, 1998: 94.

${ }^{3}$ Defterde bu çalışma için incelenen bikaç yerinde 'elçinin getirdiği, götürdüğü' şeklinde birkaç örneğe rastlanmıştır. Dolayısıyla tüm verilerin muhallefat kaynaklı olmayabileceğinin de altını çizmek gerekir. Bkz. TS.MA.d.02321.0001.00 s. 13b,14b.
} 


\section{Defterin Verilerinin Değerlendirilmesi}

Yukarıda belirtildiği gibi bu çalışma için künyesi verilen defterin 2. ve 16. sayfaları arası kullanılacaktır. Defterin geri kalan kısımları başka bir çalışmanın konusu olacaktır. Defterin birebir çevirisi çalışmanın sonunda ekler kısmında yer alacaktır.

Defter incelendiğinde sepetler, sandıklar ve çuvallar içinde giyimden ev eşyasına, mutfak gereçlerinden silahlara pek çok türde eşyanın envanterinin tutulduğu anlaşılmaktadır. Bunların kimin muhallefatından geldiğine dair bilgi bulunmamaktadır. Sadece hazineye kaydedilirken tutulduklarına dair bir yorumda bulunmak mümkündür. Fark edilen bir başka durum, bu eşyaların belirli bir düzene göre sandıklara yerleştirilmediğidir. Bazen bir giyim eşyasının bir mutfak eşyasıyla aynı sandığa yerleştirildiği görülmektedir. Bu da toplu bir sayım üzerine defterin tutulma ihtimalinden çok yeni eşyalar geldikçe sandıklara çuvallara yerleştirilip kayıt altına alınması ihtimalini düşündürtmektedir.

Defterde rastlanılan giyim eşyaları kategorisinin içine terlikten başlığa kadar geniş bir yelpaze dikkati çekmektedir. Bunlar, dönemin giyim tarzı ve kullanılan kumaşları ilgili fikir sunacak mahiyettedir. Mesela diba kaftan, atlas kutni kaftan, zenne kaftanı, atlas kaftan; çuka ferace, sim şâtır kuşağı, Kıbrıs kuşağı, Acem kuşaklı̆̆ı; beyaz ihrâm, beyaz boğasi Ka'be ihrâmı, harir beyaz ihrâm, kırmızı Cezayir ihrâmı; hamam gömleği; mütenevvi cübbe don fistan; kürklü entari, Helaliye entari; Basra kerrakesi, beneviş çuka kerrake; siyah puşi; siyah peştamal; sarık; çukaya kaplu dilkü kürkü, Mütenevvi’a kürk; yeniçeri üsküfü; yeşil çuka yağmurluk; alaca Basra kerrake, Şamî kerrake; köhne kadife kavuk; beyaz zıbun, kedi kürklü atlas zıbın; köhne dizlik; yeşil atlas zerdeva boğazı üst; hamam gömleği; beyaz terliklik dülbend, alaca terliklik, telli terliklik; mukaddem ${ }^{4}$ kuşak; kırmızı fes; câme-şûy; sim sade sîne-bend, ${ }^{5}$ aba yağmurluk, katlavî göğüslük sim Mısırî kuşak; hamam esvâbı; kırmızı kepenek; ${ }^{6}$ semmûr kontuş; kadife kavuk; Mevlüd-i şerif esvâbları; Mütenevvi’a kolçak gibi.

Diğer yandan defterde bir hayli kumaş çeşidine rastlanmıştır. Bunlar Acem kadifesi, beyaz boğasi, bez, kılâbudânlı sarık örtüsü, kutni, Keşmirî şal, cedid Şamî dikdik, kırmızı köhne sof, sarık örtüsü, Acem kumaşı, beyaz sade, gevderî dikdik, telli Tunus şalı, Sakız şalı, Münakkaş sarık örtüsü, dülbend bürgü, Kıbrıs şalı, Acem katifesi, taraklı atlas donluk gibi.

Defterde rastlanılan mutfak ve ev içi gereçleri de bir hayli çeşitlidir. Bunların sim, fağfûrî, bakır, minakârî, mertabânî, ceviz, altın şeklinde tanımlanmasından madeni, porselen ve diğer malzemeler kullanılarak yapıldığı anlaşılmaktadır. Bunlara örnek olarak mavi hatayi ibrik altun kapaklı, çubuk sim buhûrdân, sim maşraba, gergedan bardak, ceviz bardak, Mertebânî kavanoz, fağfûrî kavanoz, fağfûrî murassa buhûrdân, Mertebânî buhûrdân, savtli ${ }^{7}$ gülâbdân, fağfûrî gülâbdân, fağfûrî murassa kapak, minakârî bardak, gergedan kemiği fincan, laciverd murassa bardak ma'a tabak, fağfûrî yekmerdi, minakârî gülâbdân, sim leğen, ibrik, yağ kutu, kebir fağfûrî, tabak fağfûrî yekmerdi ve kapak, yere kam bardak, sim şem'dân, sim gülâbdân, sim kahve ibriği, sim çiçeklik, sim tepsi, sim kadeh, yaldızlı bakır leğen ibrik, yaldızlı tas ve tebsi, matara, fağfûrî sürahi verilebilir.

Ev içi döşemelerde de çok fazla mak'ad, perde, kapı perdesi, cibinlik, çekmece, kilim, gibi eşyaların muhallefatlardan hazineye kaydedildiği görülmüştür. Bunun yanında seccadeler, namaz-gâhlar, zer bâb halılar, makramalar, bohçalar, peşkirler sayılabilecek eşyalar arasındadır. Diğer yandan bir hayli yastık, balin, yatak, yorgan, yastık yüzü gibi çeşitli şekillerde tanımlanan yatak odası eşyalarının da varlığı dikkat çekmiştir.

\footnotetext{
4 Tersane çavuşlarının feslerinin üstüne sardıkları sırmadan örtü (Parlatır, 2003: 1125).

${ }^{5}$ Gögüslük, sütyen; hayvan koşumlarında göğüs kısmına gelen kayış. (Parlatır, 2003: 1515.) Hangi anlamında bir olarak kayda geçtiğini bilmediğimiz için giyim kısmında kullanmayı uygun gördük.

${ }^{6}$ Çobanın giydiği kolsuz dikişsiz, keçeden yapılmış giyecek. (Parlatır, 2003: 986)

${ }^{7}$ Savt: ses, seda (Parlatır, 2003: 1465)
} 
Muhallefattan hazineye aktarılan mallar arasında ateşli ve delici silahların varllğı da tespit edilmiştir. Bu silahların bazılarının değerli madenlerden yapıldı̆̆ı, bazılarının süslemeli olduğu anlaşılmıştır. Mesela sim gaddare, altun kaplu sim k1lıç, altun gaddare, altun kilıç, sim balta, ok kuburu, altun sim kaplu gaddare, sim şatır gaddaresi kemerli, kara k1lıç, sim balta ve külünk, sim topuz, altun $\approx \sqrt{9}$ koltak kılıç, yay ve kepaze, Misırî sim hançer gibi. Bunun yanında ateşli silahlara da rastlanılmıştır. Cevherdâr ve Cezayir sedefkârî tüfenk, tüfenk silahı, sade namlu, nal pare tüfenk, çakmaklı tüfenk cedidi tüfenk silahı, uzun tüfenk, tüfenk kebe, sim tirkeş bağı, rûmî tüfenk silahı tespit edilen türlerdir.

At koşum aletlerine de defterde sıklıkla rastlanılmıştır. Sim çapkın eğeri, Tatar eğeri, sim eğer, sırmalı eğer, altun raht, sim kemer raht, bakır çapkın rikab, sırmalı eğer, heybe ile gemler, köhne çuka çultar, kırmızı çuka çultar, beyaz dizgin, sim kamçı örnek olarak verilebilir.

Defterde çok sık olmamakla birlikte süs ve takı eşyaları ya da kişisel eşyalara rastlanılmıştır. Bunlar arasında Mercan, Yeman, kalembek, kılbenk, incülü, 'anber tesbih olarak tanımlanan çeşitler vardır. Bir miktar da pîrûze (fîrûze) kaydı vardır.

Defterdeki veriler daha önce de belirtildiği gibi son derece çeşitlidir. Hayatın her alanına dair ipuçlarına dair verilerin izlerini buradan sürmek mümkün olabilmektedir. Mesela sımalı cüzdan, yancık, hurde pîrûze bir mikdar, sim enselik, Kitâb-1 cild, Kâbe örtüsü parça, murassa kelâm-1 'izzet, Sancağ1 şerif kelâmı 'izzeti, sim sade sîne-bend, nâme kiseleri, tor ${ }^{8}$ kese, câmedânları ve zırhlar, kandil ile ok aded, Tunus kisesi, zihgirlik, köhne alaca şukka-bend, balık dişi, kaplan post, kâfir bayrağı, tuğ, sandık, çekmece, saat, zere, zurna, bakır sây-bân topları, tob yelken bezi, sim vezne, tel, iri incü tob, incülü küçük tob, götürdügü hamam topları, bayrak sim, iri hamam kolu sim, iri sim bayrak, defterler ve kâğtlar, sim şadırvan dilleri, sim şadırvan eşyaları, bülbül kafesi defterde tespit edilen diğer eşya çeşitleri arasında bulunmaktadır.

Ek:

$2 \mathrm{a}$

\section{Hüve'l-bâkî}

1076 senesi mâh-1 Muharreminde muhallefâtdan gelan eşyalar yeniden defter olunub bu minvâl üzere sandıklara ve sepetlere vaz' olunmuşdur.

Birinci sepet

Beyaz dizgin aded 3, Sim kamçı aded 3, Tor kese aded 4, Tunus kisesi aded 1, Cüzdân aded 1, Tor uçkur aded 1, nâkıs tesbih aded 1, kolan kuşak aded 1, Destvân aded 29 , Sırmalı tirkeş aded 2, Şamî çapkın zilposu aded 1, Sim şâtır kuşağı aded 8, Sim tirkeş bağı aded 8, Sim balta aded $1,(\hat{,})$ hançer aded 1 , Sim vezne aded 1 , Sim topuz aded 1 , Sim zincir aded 2, Hançer tuğu aded 3, Sim kilıç bendi aded 1, Tazı haltası aded 4, Sim kemer ve çapkın ve Çerkesi rahtı aded 1, Altın raht aded 3, Küçük kutu hurdevât aded 1, Sim sade raht başlı̆̆1 aded 5, Sim sade sîne-bend aded 4, Küçük sepet içinde olan eşyalardır, Murassan kelâm-1 'izzet aded 1, Sancağ1 şerif kelâmı 'izzeti aded 1, Minalı gülâbdân aded 1, Savtlli ${ }^{10}$ gülâbdân aded 1, Altın hançer aded 1, Sim enselik aded 1, Mercan tesbih aded 2, Yemen tesbih aded 2, İncülü tesbih aded 1, 'Anber tesbih aded 1, Yeşim murassa divid ma'a tabak aded 1, Murassa küçük fincan ma'a tabak aded 1, Yeşil güllü fağfûrî fincan aded 1.

$2 \mathrm{~b}$

İkinci sepet

\footnotetext{
${ }^{8}$ Balık ağ1 ve örgü (Parlatır, 2003: 1728).

${ }^{9}$ Dest-vâne: savaşta ele takılan demir eldiven (Parlatır, 2003: 338).

10 Savt: ses, seda (Parlatır, 2003: 1465).
} 
Münakkaş ve atlas ve Yemenî bohçalar aded 10, Yemenî yorgan yüzü aded 13, Mütenevvi'a cübbe don fistan aded 13

Üçüncü sepet

Çatma top yasdık çift aded 6, Halebî cedid dikdik aded 8, Cezayir sancağı cedid 2, Kitâb1 cild aded 4, Beyaz terliklik tob aded 13.

Dördüncü sand1k

Mütenevvi’a Şamî dikdik aded 19 (2 aded çıarılmış ) 17, Şamî şukka-bend aded 4, zerduhte abâyi aded 2.

Beşinci kırmızı çuka sandık

Suzenî ve boğasi mak'ad aded 3, Mütenevvi'a peşkirler aded 7, Beyaz ihrâm aded 5, Hamam gömleği aded 9.

Altıncı kırmızı çuka sandık, Mütenevvi cübbe don fistan aded 45.

Yedinci sepet

Hamam döşemesi çift aded 10, Havlu makraması çift aded 15, Mütenevvi’a kürk aded 4, Çuka ferace aded 3,

Sekizinci sepet, 'Acem kadifesi donluk aded 5, Beyaz boğasi tob aded 36, Câme-şûy çift aded 25, Bez tob aded 4, Kilâbudânlı sarık örtüsü aded 2.

$3 \mathrm{a}$

Dokuzuncu sepet

Çêkmece saati aded 2, Câme-şûy çift aded 6, S1rmalı --- aded 6, قتونى tob aded 3, Yorga bakır rikâb çift aded 4, Yeniçeri üsküfü aded 2, Basra kerrakesi aded 1, Kutni tob aded 2, Yalın aded 1, Zer düz iskemle zarfı aded 1, Köhne mak'ad aded 2, Kulle ? saat aded 1, Maşraba aded 3, Onuncu beyaz derili sandık, Tüfenk sandığı aded 15.

On birinci sepet

Yüz yasdığ1 aded 10, Cezayir ihrâmı aded 4, Yeşil seccade aded 1, Yeniçeri üsküfü aded

2, لص kırmızı aded 20, Kırmızı fes aded 8, Çukaya kaplu dilkü kürkü aded 1.

On ikinci sepet

Kıbrıs kuşağ1 aded 4, Münakkaş makrama bohça aded 1, Keşmirî şal aded 16, Kıbrıs tıraş peşkiri aded 1, Berü makramalık tob aded 1, El makramaları aded 15, Alaca tefarik aded 1, Kıbrıs peşkiri aded 1, Misırî makrama çift aded 6, Kerrakelik harîr aded 1, 'Acem kuşaklı̆̆1 aded 4, Mardin teğeltiliği aded 3, Cedidi Şamî Dikdik aded 6, Fağfûrî bardak aded 1, Bez makrama aded 8, Siyah puşi aded 1, Siyah peştamal aded 1, Yemeni yorgan yüzü aded 1, Tire peşkiri aded 1.

On üçümcü sepet

Köhne sarık aded 5, Murassa eğer aded 1, Köhne çakşır aded 2, Köhne kadife kavuk aded 3, Beyaz zıbun aded 2, Kırmızı köhne sof aded 1, Yemeni yorgan yüzü aded 2, Yelpaze aded 1, Sedefkârî iyne aded 2, Makramalık bez tob aded 1, Yemeni şerbet makraması aded 9, Sarık örtüsü aded 2, 'Acem kumaş1 aded 1.

$3 \mathrm{~b}$

Ondördüncü beyaz tahta sandık

Köhne zıbun entari aded 5, Beyaz sade aded 3, ve bazı hurdevât olur

On beşinci sepet

Yemenî perde aded 1, Alaca ezrak aded 1, Suzenî makrama aded 2, Kiçe seccade aded 1, Darayî perde aded 1, Zer bâb halı aded 1, Beyaz kırmızı makrama aded 2, Gevderî seccade aded 1 
Şali mak'ad aded 1, Köhne kadife mak'ad aded 2, Kıbrıs kumaşı mak'ad aded 2, Kadife Münakkaş seccade aded 1, Aba tob aded 1, Alaca Türkman çultarı aded 2.

On altınc1 sepet

Münakkaş yüz yasdığı aded 20, Der düz yüz yasdığı aded 1 .

On yedinci sepet

Gevderî dikdik aded 3, Zer --- yüz yasdığı aded 5, Kırmızı çuka çakşır aded 5, Beyaz ihrâm aded 1, Kıbrıs kumaşı mak'ad aded 1, Yeşil çuka yağmurluk aded 1.

Sekizinci sandık

Sim Misır gaddaresi aded 2, Sim kilıç aded 1, Sade namlı kılıcı aded 1, Sim topuz aded 7, Sim balta aded 1, Sim buhûrdân ve gülâbdân aded 1, Harir Mardin peşkiri aded 4, Mardin makraması çift 4, Mardin perdesi aded 1, Kelâm-1 'izzet aded 1, Def'a Kelâm-1 'izzet aded 4, kitâb-1 cild aded 3, 'Acem tefaruğu aded 16, Ber-vechi alaca aded 3, Defa Harir peşkiri aded 1, Kıbrıs tıraş peşkiri aded 3, makrama aded 1, Mardin yasdığı köhne çift aded 4, Kıbrıs şalı aded 13, Yemeni bayram يِّ aded 1, Halebî dikdik aded 3, Halebî şukka-bend aded 1, Zer ---beyaz son dikdik aded 2, Alaca Basra kerrake aded 2, Basra şukka-bendi aded 1, Telli Tunus şalı aded 9, Mukaddem ${ }^{11}$ kuşak aded 16, Kıbrıs kuşağ1 aded 28, Fağfûrî buhûrdân aded 1, Ber-vechi alaca aded 10, Harir peşkir aded 4, Keşmirî şal aded 2, Çiçekli kadife parça aded 2, Karınca ? ayağ1 peşkir aded 1, Yemeni namazgâh aded 1, Alaca serefce peşkiri aded 4, Alaca Kıbrıs peşkiri aded 1

$4 \mathrm{a}$

Sakız şalı aded 5, Münakkaş Sakız mukaddemi aded 5, Telli Bursa tefaruğu aded 3, Al telli tefarik yorgan yüzü aded 1, Kırmızı telli Kıbrıs tıraş peşkiri aded 29 aded 11, Kırmızı telli sakız şalı aded 2, Beyaz telli Kıbrıs kumaşı aded 1, Câme-şûr çift aded 8, Münakkaş makrama aded 2, Köhne sarık aded 3, Münakkaş sarık örtüsü aded 1, Murassalıca rekdân balık dişi aded 2, Kemik rekdân aded 2, Yeşim hançer kabza aded 1, Kebîr mercan tesbih aded 2, Evsat boyu mercan tesbih aded 4, Sagîr mercan tesbih aded 1, 'Anber tesbir aded 2, Sim kabzalı biçak aded 1, Sim zincir aded 1, Sim tirkeş zinciri aded 1, Kilbenk tesbih aded 2, Fağfûrî gülâbdân aded 1, Kitâb cild aded 7, Kırmızı çuka üzere der düz yasdık aded 4, Yağ kutusu aded 5, Altın veznesi aded 1 .

On dokuzuncu sepet

Mütamel köhne çatma tasdık aded 13, Köhne Dikdik aded 1, Suzenî yasdık aded 1, zerduhte abayi aded 3, Beyaz ihrâm aded 3, Tire döşemesi aded 3.

Yirminci sepet

Yaldızlı leğen aded 3, Yaldızlı ibrik aded 3, Yaldızlı tıraş tası aded 3, Yüz yasdığ1 aded 3, Dülbend bürgü, Havlu döşeme aded 5, Havlu hamam gömleği aded 7, Mütenevvi’a boğasi aded 9, Beyaz çuka donluk aded 1, Beyaz ihrâm aded 1, Misır peşkiri aded 1, Tire gömleği aded 1, Basra seccadesi aded 1, Gazze teğelti aded 2.

Yiğirmi birinci sepet

Kırmız1 تَّ donluk aded 4, Fağfûrî leğen ibrik aded 1, Yekmerdi fağfûrî aded 3, Küçük tabak aded 2, Şamî hare tob aded 16, Gazze peşkir aded 1, Gazze makraması aded 1, Beyaz harir ihrâm aded 4, Ka'be örtüsü parça aded 1, Havlu döşeme aded 1, Havlu makrama aded 10, Şamî köhne Dikdik aded 1, Bez makramalık tob aded 1, Şal aded 3, Münakkaş makrama bohça aded 1

$4 \mathrm{~b}$

11 Tersane çavuşlarının feslerinin üstüne sardıkları sırmadan örtü (Parlatır, 2003: 1125). 
Yiğirmi ikinci sandık, Yüz yasduğı aded 1, Çuka şukka-bend aded 1, Çuka çultar aded 1, Yorgan aded 2, Aba yağmurluk aded 1, Alaca kutni mak'ad aded 1, Ezrak aded 1, Seccade-i 'Acem aded 1, Yirğirmi üçüncü sandık, Sof çakşır aded 11, Çuka çakşır aded 5, Çatma yasdık aded 16, Kumaş mak'ad aded 1, 'Acem dibası yasdık aded 3, Beyaz atlas zer-duhte yasık aded 1, Kırmızı çuka zer-duhte yasdık aded 1, Ağır Mardin yasdığı aded 2, zer-duhte kadife yasdık çift aded 2, 'Acem zer bâbî mak'ad aded 1, Kaliçe-i zer bâb aded 1, Came-şûy boğça aded 4, Beyaz ihrâm aded 14, Sim Misırî kuşak 4, zer-duhte ocak yaşmağ1 aded 1.

Yiğirmi dördüncü sandık

Mütenevvi'a kumaştan zenne entarileri aded 20, Mütenevvi’a zenne kaftanı aded 9, Kedi kürklü atlas zıbın aded 1, Yüz yasdığ1 aded 1, Suzenî mak'ad aded 1.

Yiğirmi beşinci sandık

Came-şûy boğça aded 1, Münakkaş dülbend örtüsü aded 6, Telli makramalık bez aded 1, Abdest makrama aded 1, Münakkaş makrama aded 7.

Yiğirmi altıncı sandık

Kırmızı Cezayir ihrâmı aded 9, Kırmızı Cezayir velinçesi aded 10.

Yiğirmi yedinci sandık

Sim sineklik aded 5, Sade sineklik aded 2, Dizgin aded 4, Köhne tapkur aded 3, Dülbend alaca terliklik aded 5, Kıbrıs şalı aded 7, Câme-şûy ve makrama boğça aded 1, Mardin perdesi aded 1, Serefce peşkiri aded 1, Kıbris peşkiri aded 1, Kumaş mak'ad aded 2, Kadife küçük mak'ad aded 1

Yiğirmi sekizinci sepet

Sim 55 aded 2, Altun küf üzengiler çift aded 5.

$5 \mathrm{a}$

Yiğirmi dokuzuncu sepet

Kirmiz1 $=\mathbf{=}$ tob aded 7, İri boy divid aded 4, Murassalıca sim divid hokka aded 1, Kitâb-1 cild aded 20, Altun küf üzengi çift aded 1, Çatma mak'ad aded 1, Yemeni yorgan yüzü aded 3, Zer bâb seccadesi aded 1, Suzenî mak'ad aded 2, Beyaz Tire cibinliği aded 1, Kıbrıs cibinliği aded 1.

Otuzuncu sandik

Sim altun buhûrdân murassa aded 1, Fağfûr murassa badak aded 1, Fağfûrî küçük yekmerdi ma'a, tabak aded 14, Fağfûrî buhûrdân aded 1, Fağfûrî ibrik aded 1, Fağfûrî kâse aded 3, Fağfûrî leğen aded 1, Metabânî buhûrdân aded 1, Beyaz ihrâm aded 1, Telâtîn bardak aded 3, $\operatorname{Sim} 2$ a a a ded 1, Bir kutu içinde Firengi şişeler aded 1, Fağfûrî hurde yekmerdi aded 7.

Otuz birinci sepet

Kutni mak'ad aded 3, Zer bâb 'Acem mak'ad a aded 1, Kırmızı Cezayir ihrâmı aded 1.

Otuz ikinci sepet

Serefce peşkir aded, Mardin kahve makraması çift 5, Harir peşkir aded 5, Kıbrıs peşkir aded 2, Gazze peşkir aded 1, İplik peşkir aded 4, Def a Mardin peşkir aded 1, Halebî dikdik aded 5, Halebî şukka-bend aded 1, Çatma tob aded 1, Kırmızı harir ihrâmı aded 3, Yüz yasdığı aded 5.

Otuz üçüncü sepet

Köhne çatma yasdık aded 9, Çatma top aded 1, Hamam döşeme aded 2, Hamam gömleği çift aded 2, Beyaz harir ihrâm aded 1, Kemhâ sofra aded 1, Beyaz bohası Ka'be ihrâmı aded 6, Münakkaş dülbend örtüsü aded 4, Tire hamam esvâb1 çift aded 1, Misırî peşkir aded 2, Tire 
Döşemesi aded 2, Misırî beyaz yemek makraması aded 7, Misırî peştamal çift aded 3, Küçük namaz-gâh aded 1, Kibris kuşağı aded 7,

Otuz dördüncü sand1k

Câme-şûy çift aded 3, Yüz yasdığ1 aded 1, Kahve makrama aded 5, Germesûd boğasi aded 3, Beyaz Şamî hare aded 1, Kıbrıs peşkir aded 1, Alaca iplik peşkir aded 1, Namaz-gâh aded 1, Mardin teğelti aded 1, Hurde bohça aded 5, Hançer tiği aded 2, Kllâbdânlı yen tob aded 1, Kıbrıs şalı aded 2, Beyaz harir Kıbrıs makrama aded 2, Basra yasduğu aded 2, Çatma yadık çift aded 1, İbrişim seccade aded 3, Der düz seccade aded 1, Zerbâb kaliçe aded 3.

$5 \mathrm{~b}$

Otuz beşinci sepet

Yorgan aded 3, Cezayir ihrâm aded 1, Cezayir velinçe aded 1, teğelti aded 1, 'Acem döşemesi aded 1, Köhne dikdik aded 1 Kumaş mak'ad aded 2.

Otuz altıncı sandik

Keşmirî şal aded 126, Sim gülâbdân aded 1.

Otuz yedinci sepet

Tefarik yorgan aded 4, Çuka seccade aded 1, Katife mak'ad aded 1, Siyah namaz-gâh aded 1, Tire makraması aded 2, Münakkaş sim raht aded 9, Sim zincir aded 2, Sim yelân ${ }^{12}$ aded 1.

Otuz sekizinci sepet

Mavi Hatayî ibrik altun kapaklı aded 1, Çubuk sim buhûrdân aded 1, Sim maşraba aded

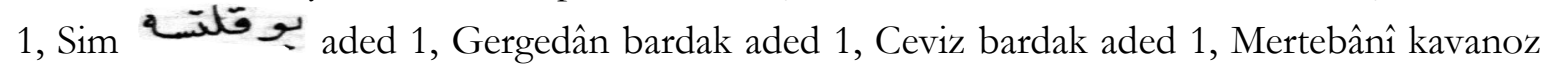
aded 1, Fağfûrî kavanoz aded 2, Fağfûrî murassa buhûrdân aded 1, Mertebânî buhûrdân adde 1, Fağfûrî gülâbdân aded 3, Fağfûrî murassa kapak aded 1, Minakârî bardak aded 1, Laciverd murassa bardak ma'a tabak aded 1, Fağfûrî yekmerdi aded 5.

Otuzdokuzuncu sandik

Mütenevvi'a kitâb-1 cild aded 62 .

Kırkınc1 sepet

Hamam gömleği aded 24, Hamam döşemesi aded 7, (okunamıyor) makraması aded 33, Siyah peştamal çift aded 2 .

Kurk birinci sepet

Suzenî mak'ad aded 1, Katf ${ }^{13}$ mak'ad aded 1, Seccade-i zerbâb aded 1, Zerbâb mak'ad aded 1, Basra seccadesi aded 1.

Kırk ikinci sandik

Çatma yasdık çift aded 7, Köhne kumaş entari aded 4,

$6 a$

Kırk üçüncü sandık

Çatma yasdık aded 4, Acem katifesi tob aded 2, Kırmız1 peşkir aded 1, Divid aded 2, Havlu peşkir aded 1, Tire peşkiri aded 1, Kubbe peşkir aded 1, Yüz yasdiğı aded 5 .

Kırk dördüncü beyaz sandık

Bir heybe ile gemler, Bakır evânîleri, Tob yelken bezi aded 3 .

\footnotetext{
12 Şampiyonlar pehlivanlar (Parlatır, 2003: 1829).

13 Meyve toplama (Parlatır, 2003: 859)
} 
Kırk beşinci sepet

Çakmaklı tüfenk aded 5, Kubbe seccade aded 2, Çuka sagîr puşi aded 3, Köhne Haleb dikdiği aded 3, Suzenî mak'ad aded 1, Mak'ad kutni aded 2, Kumaş entari aded 1, Atlas kaftan aded 1, Boğasi kapama aded 1, Çuka çakşir aded 1, Basra kerrake aded 1, Şamî kerrakelik aded 1,Üşek dane aded 2, Münakkaş makrama aded 28, Câme-şûr çift aded 5.

Kirk altınc1 sepet

Câme-Şûy çift aded 10, Kıbrıs kuşağı aded 18, Hamam esvabı çift aded 2, Mardin peşkiri aded 1, Mardin perdesi aded 2, Serefce peşkiri aded 1, Kırmızı harir ihrâm aded 1, Basra yasduğu çift aded 2, Siyah safirî hançer kını aded 4, Gümüş bıçak aded 3, Telâtîn kınlı bıçak aded 3, Gergedan kemiği fincan aded 1, Bakır safâ aded 1, Çift yorgan yüzü aded 6, Havlu makrama çift aded 6, Tiraş peşkiri aded 3.

Kirk yedinci sandik

Mor çuka semmûr kafası kürk aded 1, Şamî Dikdik aded 1, Zer-duhte Dikdik aded 1, Sof çakşir aded 2, Çuka çakşir aded 1, Boğasi sofra aded 1, Köhne Dikdik aded 3, Alaca makrama aded 9, Müsta'mel tire peşkir aded 2, Harir ihrâm beyaz aded 1, Beyaz ezrak aded 3, Şamî hare donluk aded 15, Beyaz boğasi aded 4, Ber-vechi alaca aded 6, Kılbenk tesbih aded 20, Kibris peşkiri harir aded 2, Köhne sofra aded 2, Köhne peşkir adde 1, Boş bohca aded 3, Siyah puşi aded 1, Zer-duhte boğça aded 2, Misırî peştamal aded 3, Misırî makrama aded 3, Keşan kutnisi aded 1, Münakkaş makrama aded 24, Dülbend örtüsü aded 3, Cezayir şalı aded 7, Sakız kumaş1 aded 2, Tor akçe kise aded 6, Makramalık bez tob aded 6

$6 \mathrm{~b}$

Kurk sekizinci sandik

Çuka mak'ad aded 4, Diba mak'ad aded 1, Çatma mak'ad aded 1, Kutni mak'ad aded 1, Kitâb-1 cild aded 7, Hamam esvâbı aded 5, Çakmaklı tüfenk aded 4, Çatma yasdık aded 1, Münakkaş makrama boğça aded 1, Çatma cedid yasdık çift aded 3, Bez tob aded 3, Bakır 'alem aded 1, Sim kilîdân aded 1, Kırmızı Mardin peşkiri aded 1, Harir peştamal aded 1, Köhne Kıbrıs şalı aded 2, Hurde kahve makramaları aded 3,

Kirk dokuzuncu sepet

Kürklü entari aded 1, Köhne kapama aded 1, Defterler ve kâğıtlar, Tob yelken bezleri.

Ellinci sepet

Kırmızı kadife yasdık aded 4, Köhne çatma yasdık aded 22, Çuka yasdık çift aded 2, Namaz-gâh, aded 1, Köhne Mardin perdesi aded 1, Köhne çuka boğaz kürk aded 1, Ocak yaşmağ 1 aded 1.

Elli birinci sepet

Sincab abdest kürdeği aded 1, Yeşil atlas zerdeva boğazı üst aded 1, darayi kapama aded 1, Köhne kavuk aded 2, Kutni mak'ad aded 3, Yemeni mak'ad aded 2, 'Acem katifesi tob aded 2, Köhne boğça aded 3, Alaca namaz-gâh aded 1, Ezrak aded 3, Köhne dizlik aded 2.

Elli ikinci sandık

Sim balta aded 2, Külünk sim aded 1, Sim kemer ve Çerkesi raht ve cedidi aded 30, Topuz aded 3, Bakır ve altun küf rikâb çift aded 12, Çapkın rikâbı çift aded 2, Sim biçak aded 3, Sim hançer aded 1, Demir kolçak ve

Elli üçüncü sepet

Hezârân kalkan aded 1, Yasdik çift aded 1, Mardin yasduğu aded 1, Atlas yasdık aded 1, Mardin peşkiri aded 1, Kıbrıs kuşağı aded 2, Ber-vechi aded 2, Kolan kuşak aded 1, Keşmirî şal aded 1, Abdest makraması aded 1, Fağfûrî kâse aded 2 (biri mavi), Beyaz Hatayî tabak aded 1, 
Beyaz yekmerdi aded 3, Kubbe yekmerdi aded 1, Fağfûrî gülâbdân aded 1, Beyaz güllü yekmerdi aded 1, Bir kutu içinde küçük fağfûrî tabak aded 8, Mertebânî tabak aded 1, Fağfûrî ibrik aded 1, Fağfûrî evsat tabak aded 2

$7 \mathrm{a}$

Elli dördüncü 2, L havic hane

Fağfûrî iri tabak aded 12, Fağfûrî hurde tabak aded 41, Mavi ibrik aded 1, Kırmızı ibrik aded 1, Alaca ibrik fağfûrî aded 1, Fağfûrî leğen ibrik aded 1, Fağfûrî acem ibriği aded 1, Fağfûrî gülâbdân aded 1, Fağfûrî buhûrdân aded 1, Murassa gülâbdân aded 1, Billur murassa gülâbdân ve tabak aded 1, Fağfûrî havme ${ }^{14}$ aded 1.

Elli beşinci havic hane

Mertebânî leğen aded 1, Fağfûrî balya ${ }^{15}$ aded 2, Fağfûrî kâse aded 2, Fağfûrî yekmerdi aded 12, Murassa yekmerdi ve tabak aded 1, gergedârî yekmerdi ve tabak murassa aded 1, Savtlı Fağfûrî divid aded 1, Evsat Mertebânî yetmerdi aded 6, Mertebânî kâse aded 3, Murassa fağfûrî buhûrdân aded 2 .

Elli altınc1 sandik

Kubbe seccade aded 3, Çuka perde aded 3, Katife mak'ad aded 1, Mütenevvi'a yorgan aded 2, Bez çarşeb aded 6.

Elli yedinci sandik

Münakkaş yüz yasdığı aded 5, Yorgan aded 2, Beyaz ihrâm aded 1, Mütenevvi'a boğça aded 2, Hindî katife kapu perdesi aded 1, Harir kırmızı ihrâm aded 1, Mardin perdesi aded 3, Mardin peşkiri aded 2, Mardin kahve makraması aded 5, Misır peşkiri aded 1harir peşkir aded 1, Misır makraması aded 3, Câme-şûy boğça aded 1.

Elli sekizinci sepet, Kırmızı çuka çultar aded 13.

Elli dokuzuncu sandik

Kırmızı çuka çultar aded 5, Siyah çuka namaz-gâh aded 1, Kubbe seccade aded 2, Alaca kadife yasdık aded 1, Çuka ocak yaşmağı aded 1.

Altmışıncı sandık

Câme-şûy çift aded 5, Mor çuka zer düz zilpuş aded 1, Zer-duhte katife dikdik aded 1, Şamî zilpuş aded 2, Köhne Dikdik aded 1, Helaliye entari aded 5, Yemeni makrama boğça aded 1, Alaca kaftan aded 5, Kebîr Fağfûrî tabak aded 1, Kebîr Mertebânî tabak aded 1, Beyaz telli alaca kaftan aded 2, Sof çakşir aded 3, Harir alaca peşkir adde 1, Murakka ${ }^{16}$ boğça aded 7.

$7 \mathrm{~b}$

Altmış birinci sandık

Köhne çuka yasdık çift sded 11, Çatma cedid yasdık çift aded 1, Serâser yasdık aded 5, Mardin yasduğu aded 1, Çuka zer düz seccade aded 1, Harir seccade aded 1, Gevderî seccade aded 1, Serefce peşkiri aded 1, Mavi Mardin peşkiri aded 1, Sarık örtüsü aded 5, Hindî kaliçe-i zerbâb aded 1, Hamam esvâbı çift aded 1, Câme-şûy boğça aded 1.

Altmış ikinci sandık

Hamam esvabı çift aded 5, Münakkaş yüz yasdığ1 aded 5, Harir beyaz ihrâm aded 2, Beyaz Münakkaş seccade aded 1, Came-şû y boğça aded 3, Boyalı ve Münakkaş makrama boğça aded 1, Zer-duhte sandal boğça aded 1, Ta'am makramalığ tob aded 1, Dülbend örtüsü aded 1, Telâtîn zer-duhte bardak aded 1, Mütenevvi'a bohça aded 7 .

\footnotetext{
14 Tasarruf dairesi veya yeri (Parlatır, 2003: 602).

${ }^{15}$ Beze sarılı sıkı bağlanmış ticari mal (Parlatır, 2003: 154).

${ }^{16}$ Yamalı (Parlatır, 2003: 1133).
} 
Altmış üçüncü sandık

İkirlet çuka parça aded 4, teğelti aded 2, Yüz yasdığ1 aded 2, Atlas perde aded 1, Kılâbudânlı yorgan aded 1, Kırmızı Cezayir ihrâmı aded 1, Câme-şûy bohça aded 1, murassa yekmerdi ve tabak aded 2, yaldızlı tebsi aded 6, Telâtîn kâse ve tabak, Kırmızı Cezayir velinçe.

Altmış dördüncü sandık

Mütenevvi'a kumaş entari ve zıbun aded 21, Altmış beşinci sandık, Hamam esvâbı çift adde 2, Tire peşkiri aded 1, Serefce peşkiri aded 1, Entari ve zıbun aded 10, teğelti aded 4, Gevderi seccade aded 1, Zer-duhte matara aded 1

Altmış altıncı havic hane

Altun raht aded 1, Sim çapkin ve raht aded 4, Sim topuz aded 3, Sim varsak ${ }^{17}$ aded 2, Altun şiş aded 1, Sim satır aded 4, Kurban bıçağı aded 4, Sim biçak aded 3, Minakârî gülâbdân aded 1, zer-duhte 20 aded 1,Cedidi Şamî dikdik aded 39, Şukka-bend aded 1, Mercan tesbih aded 9, Yemenî tesbih aded 2, Kllbenk tesbih aded 1, Sim leğen ibrik aded 1, Sim torba aded 1, Sim tirkeş aded 3, Telli atlas mak'ad aded 2, Köhne boğça aded 4, Sedefkârî rahle aded 2, Telâtîn yekmerdi ve tabak aded 1 .

$8 \mathrm{a}$

\section{Altmiş yedinci}

Mütenevvi'a yağ kutu aded 1, Kebîr fağfûrî tabak aded 2, Hurde fağfûr tabak aded 12, Fağfûrî yekmerdi ve kapak aded 6, Fağfûrî buhûrdân aded 2, Yere kam bardak aded 1, Mertebânî tabak aded 1.

\section{Altmiş sekizinci sepet}

Şamî hare donluk aded 2, Kutni tob aded 7, Germ ü serd boğasi aded 3, Kutni keşân aded 1, Mardin peşkiri aded 1, Mardin kahve makraması aded 2, Mardin perdesi aded 1, Simalı cüzdan aded 5, Nâme kiseleri aded 12, Zer-duhte nâme kisesi aded 1, Tor ${ }^{18}$ kese aded 1, Kadife zer-duhte cüzdan aded, 'Acem kuşağ1 aded 1, Bayram böri tob aded 5, Beyaz mukaddem kuşak aded 1, Beyaz terliklik aded 3, Alaca terliklik aded 4, Telli terliklik aded 1, Köse sarık aded 2

Yeşil telli tefarik aded 1, Kıbrıs makraması aded 3.

Altmış dokuzuncu sepet

Gümüş $\circlearrowleft \circlearrowleft$ aded 2, Zihtgirlik aded 1, Sürmedân aded 1, Yemenî levc/ lûc aded 1, Hurde pîrûze bir mikdar, Yemenî tesbih aded 1, Hurde mercan tesbih aded 4, Kalembek tesbih aded 4, Beyaz Yemenî tesbih aded 1, Kırmızı Yemenî tesbih aded 1, Hurde tesbih aded 1, Saat kiseleri aded 5, Sof ferace aded 1, Semmûr kontuş aded 1, Çuka ferace aded 2, Hare gezi serhaddi aded 4, Mütenevvi'a kapama aded 5, Yüz yasdığı aded 1, Köhne Dikdik aded 1, Suzenî mak'ad aded 3, zer-duhte abayi aded 2, Taraklı atlas donlu aded 1, Mutalla sarık aded 2, Keşmirî şal aded 2 .

\section{Yetmişinci sepet}

Murakka' bohça aded 5, Münakkaş yüz yasdığı aded 1, Keşmirî şal aded 17, Tunus'dan pişkeş gelan kırmızı ihrâm aded 2, Kâ’im hâne sedtar aded 8 .

Yetmiş birinci beyaz sandik

Mütenevvi'a yorgan aded 6, Alaca seccade aded 2, Murakka' kebîr mak'ad aded 1, Çuka kapu perdesi aded 1, Siyah bornos aded 1, Beyaz sade aded 3, Alaca entari aded 1, Safiri puşi aded 1, Katife kablu çekmece aded 1

\footnotetext{
17 Yaralayıc1 alet (Parlatır, 2003: 1781).

${ }^{18}$ Balık ağ1 ve örgü (Parlatır, 2003: 1728).
} 
$8 \mathrm{~b}$

Yetmiş ikinci kılıç sandığ1

Sim gaddare aded 25, Altun kaplu sim kılıç aded 1, Altun gaddare aded 4, Altun kılıç aded 1, Altun $\bar{z} \sqrt{\underline{2}}$ koltak kilıç aded 1, Yay ve kepaze aded 8, Sim topuz aded 1, Köhne alaca şukka-bend aded 1, Mavi çuka mak'ad aded 1.

Yetmiş üçüncü sepet

Mütenevvi'a entari ve zibun aded 16, Yetmiş dördüncü sepet, Mütenevvi'a entari ve zibun aded 15, Siyah kerrake aded 1, Kirmızı kepenek aded 1

Yetmiş beşinci sepet

Câme-şûy boğça aded 1, Siyah alaca Burusa peştamal aded 10, Köhne mükemmel hamam esvabı aded 1, Köhne destar aded 16, Sâfí gömlek işi aded 27, Münakkaş makrama ve boğça aded 2, Köhne makrama boğça aded 1, Ta'am makramaları boğça aded 1, Alaca cübbe don aded 1, Sarı peştamal aded 5, Beyaz harir makrama aded 2.

Yetmiş altıncı sandık, Zer-duhte çuka zilpuş aded 10, Şamî Dikdik aded 4, Zer-duhte aded 1, Atife zer-duhte aded 1, Sırmalı sineklik aded 1, Kırmızı ibrişim nur cibinlik aded 1, Tefarik cibinlik aded 1, Beyaz Kıbris cibinlik aded 1, Hamam esvabı aded 1

Yetmiş yedinci sepet beyaz

Suzenî kebîr mak'ad aded 2, Köhne seraser mak'ad aded 2, Köhne zer aba perde aded 2, Çatma yasdık çift aded 1, Katifre yasdık çift aded 2, Kırmızı Cezayir ihrâmı aded 1, Kutni mak'ad aded 2

Köhne boğça aded 1, Köhne alaca entari aded 4, Köhne çatma yasdık aded 7

Yetmiş sekizinci sepet

Köhne çatma yasdık çift aded 7, Hindî kadife yasdık çift aded 3, Taraklı atlas cibinlik aded 1, Kutni perde aded 2, Mardin perdesi aded 1, Suzenî mak'ad aded 1, Suzenî mak'ad aded 4, zer-duhde seccade aded 1, Ocak yaşmağ zer-duhtre aded 2, Yüz yasdığ1 aded 2

$9 \mathrm{a}$

Yetmiş dokuzuncu sepet

Katlavî göğüslük çift aded 2, Firengî çekmece aded 1, Çuka münakkaş incülü balîn aded 1, Zil aded 1, Hotaz aded 1, İbrişim dizgin aded 6, Alaca Gazze peşkiri aded 1, Kırmızı harir peştamal aded 3, Atlas Münakkaş yasdık çift aded 3, Çatma yasdık çift aded 3, Mor katife yasdık aded 1, Kâr-hane tob aded 1, Kadife mak'ad aded 1.

Seksanıncı beyaz sandik

Kubbe seccade aded 2, Kırmızı harir ihrâm aded 1, Katife mak'ad aded 1, Kılâbudânlı yorgan aded 2, Serâser mak'ad aded 2, Çatma kapu perdesi aded 1, Atlas kapu perdesi aded 1, Seksan birinci küçük sandık, Câme-dânları ve zırhlar aded 7.

Seksan ikinci sepet

Câmedânile zırh aded 1, Sim eğer aded 1, Cedidi tüfenk silahı aded 5, Rûmî tüfenk silahı aded 4, Kandil ile ok aded 2, Yemek makraması aded 27, Dülbend örtüsü aded 1, Makramalık tob aded 1

Müsta'mel hamam esvâbı aded 1.

Seksan üçüncü sepet

Bayram böri tob aded 9, Kadife nâkıs tîr-keş, Hindî ¿ev aded 1, Diba mak'ad aded 1, Çiçekli kadife mak'ad aded 1, Suzenî mak'ad aded 1, Kılâbdân kenarlı Suzenî mak'ad aded 2, Kırmızı katife yasdık çift 4, tek 1, Münakkaş atlas tasdık aded 4. 
Seksan dördüncü sepet

Mütenevvi'a entari ve zıbun aded 7, Beyaz sade aded 12, Kumaş entari ve zıbun aded 8, Çuka çakşir aded 1, Kırmızı kadife bâlin aded 2.

Seksan beşinci siyah sandık

Sedefkârî çekmece aded 1, Sedefkârî divid aded 1, Hamam esvabi çift aded 1, France ayağ1 peşkir aded 1, Came-şûy boğça aded 1, Zer-duhte dülbend örtüsü aded 1, Al Mardin kahve makraması aded 1, Kadife seccade aded 1, Atlas cibinlik aded 1, Çekmece saati aded 1, Yere kam bardak aded 1, Yaldızlı bardak aded 1, Kadife kavuk aded 1, Alaca acem kadifesi tob aded 2, Balık dişi aded 1

Havlan Hindî tob aded 1, Yaldızlı hamam tası aded 1, Murassa bohça aded 1, Zer-duhte bohça aded 2, Ber vechi tob aded 5, Kıbrıs makrama aded 1, Kırmızı şal aded 1, Beyaz kahve makrama aded 1, Münakkaş sofra aded 10

$9 \mathrm{~b}$

\section{Seksan altınc1 sepet}

Beyaz çuka kerrake aded 1, Çuka ferace aded 8, Sof ferace aded 4, Beneviş çuka kerrake aded 1, Kumaş kaftan aded 6, Yere kam tabak aded 1, Zer-duhte matara aded 1, Fağfûrî sürahi aded 1, Kilim-i âdî aded 4.

\section{Seksan yedinci sandik}

Yaldızlı leğen ibrik aded 2, Çapkın sim raht aded 4, Misırî kemer kuşak aded 3, Misırî sim hançer aded 8, Sim leğen aded 1, Sim ibrik aded 2, Sim şem'dân aded 3, Sim buhûrdân aded 5, Sim gülâbdân aded 2, Sim kahve ibriği aded 1, Sim maşraba aded 1, Fağfûrî sim buhûrdân aded 1, Sim çiçeklik aded 1, Sim tepsi aded 1, Sim kadeh aded 1.

Seksan sekizinci Mertabânî havic hanesi

Kebîr Mertabânî tabak aded 10, Fağfûrî iri tabak aded 1.

Seksan dokuzuncu

Fağfûrî ibrik tabak aded 17, Kolla saat.

Doksaninc1

Kolla saat aded 1, Macari saat aded 2.

Doksan birinci akçe sandiğında

Zere ser petek aded 26, Kolçak çift aded 2

Doksan ikinci akçe sandığında

Mütenevvi’a kolçak çift aded 7, Zere sade aded 1.

Doksan üçüncü akçe sandığında

Mütenevvi'a kolçak çift aded 4, Zere sade aded 1.

Doksan dördüncü akçe sandiğında

Mütenevvi'a zere aded 4.

Doksan beşinci akçe sandiğında

Mütenevvi'a zere aded 5

$10 \mathrm{a}$

Doksan altıncı akçe sandığında

Mütenevvi'a zere aded 4.

Doksan yedinci akçe sandığında

Mütenevvi'a zere aded 5 . 
Doksan sekizinci akçe sandığında

Mütenevvi'a zere aded 7.

Doksan dokuzuncu akçe sandığında

Mütenevvi'a zere aded 5.

Yüzüncü akçe sandığında

Mütenevvi'a zere aded 7.

Yüz birinci akçe sandığında

Mütenevvi'a zere aded 4.

Yüz ikinci akçe sandığında

Mütenevvi'a zere aded 4.

Yüz üçüncü akçe sandiğında

Mütenevvi'a zere aded 7.

Yüz dördüncü akçe sandığında

Mütenevvi'a zere aded 7

Yüz beşinci akçe sandığında

Mütenevvi'a zere aded 7

Yüz altınc1

Alaca şukka-bend aded 2

Çuka çapkın zilpuşu aded 2

Köhne çuka çultar aded 1

Kırmızı kiçe aded 1

Yaldızlı bakır leğen ibrik aded 2

Yaldızlı tas ve tebsi aded 1

Münakkaş yüz yasdığ1 aded 1

Çakmaklı tüfenk aded 14

Bakır çapkın rikâb çift aded 1

Havlu peşkir aded 1

Köhne entari aded 5

Yüz yedinci

Sirmalı eğer aded 4

Sim çapkın eğeri aded 1

Sim eğer aded 1

Köhne perde aded 3

Köhne ihrâm aded 1

$10 \mathrm{~b}$

Yüz sekizinci

Kaplan post aded 18,

Yüz dokuzuncu köne sırmalı eğer aded 6 .

Yüz onuncu küçük sepet

Bazı bakır evânî

Yüz on birinci 
Sim kabara yancik aded 2

Sim çapkin eğer aded 1

Yüz on ikinci

Sade kadife yanc1k ${ }^{19}$ aded 5, Yaldızlı bakır yancık aded 2

Yüz on üçüncü kaplan post aded 7

Yay aded 1, Zurnalar birkaç

Yüz on dördüncü yaldızlı yancık aded 7

Yüz on beşinci

Sade kadife yancik aded 8

Yüz on altıncı köhnece kadife yancık aded 7

Yüz on yedinci

Mütenevvi'a uzun tüfenkler aded 15

Yüz on sekizinci

Sade kadife yancik aded 3

Köhne eğer aded 1

Namaz-gâh aded 1

Yorgan aded 1

Yüz on dokuzuncu

Kaplan postlar aded 8, Yüz yiğirminci kaplan post aded 6

$11 \mathrm{a}$

Yüz yiğirmi birinci

Köhne sade yancik aded 8

Yüz yiğirmi ikinci

Yanc1k teğeltileri aded 18, Boğasi entari aded 1, Boğasi kaftan aded 2.

Yüz yiğirmi üçüncü

Mütenevvi’a tüfenkler

Yüz yiğirmi dördüncü

Sim kabara cedidi kadife yanc1k aded 2, Köhne serâser kaftan aded 1, Mükemmel hamam esvabı aded 2, Atlas yüz yasdığı aded 1, ? kaftan polad aded 3 .

Yüz yiğirmi beşinci

Mütenevvi’a kalkan aded 10

Yüz yiğirmi altıncı köhne çatma yasdık aded 22

Balin aded 1, Kaplan post aded 2, Köhne çultar aded 1, Tüfenk silahı aded 10.

Yüz yiğirmi yedinci

Altun kilıç aded 1, Altun gaddare aded 4, Sim k1liç aded 3, Altun sim kaplu gaddare aded 3, Sim şatır gaddaresi kemerli aded 4, Altun raht aded 1, Sim gaddare aded 5, Sim ارنح إن̈vdesi aded 2, Sim şiş aded 2, Kara kılıç aded 1, Sade namlu aded 3, Sim balta ve külünk aded 7, Sim kemer raht aded 8, Sim topuz aded 3, Sim rişme aded 2.

Yiğirmi sekizinci

Köhne sim kabara yanckk aded 4

${ }^{19}$ Para kesesi (Parlatır, 2003: 1814). 
Yüz yiğirmi dokuzuncu

Çatma yasdik aded 2

Mardin yasdığ1 çift aded 2, Balin aded 1, Çuka çakşır aded 1, Suzenî mak'ad aded 1, Köhne kaftan aded 3, Diba kaftan aded 2, Çuka ferace aded 1, Atlas kutni kaftan aded 10, Kumaş donluk aded 6, Kutni tob aded 3, Acem kuşaklığı aded 2, Destvân aded 4, Hamam gömleği aded 1, 'Acem serâseri aded 1, Tire peşkiri aded 1, Beyaz boğça aded 2, Kıbrıs peşkiri aded 1, Kıbrıs şalı aded $1, \hat{A}$ hen ${ }^{20}$ topuz aded 3

$11 \mathrm{~b}$

Yemenî seccade aded 1, Münakkaş seccade aded 1, Gömleklik bez tob aded 7.

Yüz otuzuncu

Alaca terliklik aded 6, Kıbrıs makrama aded 17, Def'a Kıbrıs şalı aded 4, Tefarik makrama aded 2, Münekkış boğça aded 1, Sim buhûrdân aded 1, Sim tabak aded 1, Murassa ve Zer-duhte boğça aded 2, قُفيس top aded 1, 'Acem kuşaklığ1 aded 4, Alaca Bağdadî aded 1, Kırmızı çuka yağmurluk aded 1, Sim balta aded 1, Kutni mak'ad aded 1, Çuka perde aded 1, Sadefkârî divid aded 1, Serefce peşkiri aded 1, Beyaz boğasi aded 3, Sakız kemhasi aded 2, Bursa yasdığı çift aded 1, Suzenî mak'ad aded 1, Kahve makraması aded 15, Came-şûy çift aded 4, Köhne boğça aded 2 .

Yüz otuz birinci

Sim gaddare aded 6, Altun kilıç aded 1, Altun gaddare aded 1, Ok kuburu aded 2, Câmeşûy çift aded 1, Makramalık bez tob aded 1, Kıbrıs makraması çift aded 2, Beyaz boğasi aded 2, Siyah boğasi aded 1, Sim toplu hotas aded 1, ? aded 2, Sim 'alem aded 1, Bakır 'alem aded 1.

Yüz otuz ikinci

Zer-duhte dikdik aded 1, Şamî dikdik aded 4, Şamî şukka-bend aded 4, Beyaz dülbend aded 3, Altun kılıç aded 1, Bakır sây-bân topları aded 11, Köhne seccade aded 1, Zere aded 1, Kırmızı Cezayir ihrâmı aded 1, Namaz-gâh aded 1, Köhne mak'ad aded 1.

Yüz otuz üçüncü

Köhne mak'ad aded 2, Kalkan aded 2, Defa seccade aded 1, Kâfir bayrağ1 aded 1, Tuğ aded 3, Yasdik aded 2.

Yüz otuz dördüncü

Mertebânî tabak aded 11, Fağfûrî iri tabak aded 5, Küçük kit'a murassa yekmerdi ve tabak aded 1

Yekmerdi aded 1, Küçük tabak aded 2, Kırık yekmerdi aded 2.

Yüz otuz beşinci

Evsât Fağfûrî tabak aded 5, Hurde Fağfûrî tabak aded 1, Defa hurde tabak aded 7, İri kâse aded 2, Evsât yekmerdi aded 17, Sim kâse aded 6

$12 \mathrm{a}$

Yüz otuz altıncı dizili ağaç sandık

Sim kabaralı yancik aded 4

Yüz otuz yedinci dizili ağaç sandık

Sim kabaralı yancik aded 5

Yüz otuz sekizinci dizili ağaç sandık

Sim kabaralı yancık aded 3

${ }^{20}$ Demir (Parlatır, 2003: 52). 
Yüz otuz dokuzuncu dizili ağaç sandık

Sim kabaralı yanc1k aded 3

Yüz kırkınc1

Sim kabaralı yancik aded 3

Diba yancık aded 3, Bakır yancık aded 1

Yüz kırk birinci sepet

Zer-duhte yasdık çift aded 2, Çatma yasdık çift 2 aded 1, Mardin yasduğı aded 5, Katife iskemle zarfı aded 1, Kırmızı çuka perde aded 1, Köhne zer aba perde aded 1, Köhne kutni perde aded 1, Kilâbdânl yorgan aded 5 .

Yüz kırk ikinci sepet

Mütenevvi’a kılândâlı yorgan aded 10

Yüz kırk üçüncü

Mütenevvi’a kılândâlı yorgan aded 10

Yüz kırk dördüncü

Mütenevvi'a k1lândâlı yorgan aded 6

Tefarik yorgan aded 2

Yüz kırk beşinci sandık

Tefarik yorgan 6

Yüz kırk altıncı sandık

Tefarik yorgan 3 aded

Kebîr kırmızı çuka mak'ad aded 3

Yüz kır yedinci sandik,

Kırmızı çuka kebîr mak'ad aded 3

Suzenî mak'ad aded 3

$12 \mathrm{~b}$

Yüz kır sekizinci sandik

Kırmızı Cezayir velinçesi aded 12

Yüz kırk dokuzuncu

Kırmızı Cezayir velinçesi aded 5, Kırmızı Cezayir ihrâmı aded 2, Zer-bâb seccade aded 2, İbrişim kaliçe-i mak'ad aded 3.

Yüz ellinci uzun beyaz tahta sandık

Cevherdâr ve Cezayir sedefkârî tüfenk aded 20

Yüz elli birinci uzun beyaz tahta sandık

Nal pare tüfenk aded 22

Yüz elli ikinci akçe sandığında

Mütenevvi'a zere aded 4

Yüz elli üçüncü akçe sandığında

Münevia zere aded 4

Yüz elli dördüncü sandık

Kahverengi çuka köhne semmûr kürk aded 1, Saray çuka köhne semmûr kürk aded 1, Sof sergendi? Aded 1, Atlas üst aded 3, Mütenevvi'a kemer aded 17, Kiyemhâne destar aded 16, Siyah kadife bakır yancık aded 1, Zer-duhte köhne yancık aded 1, Köhne serâser yancık aded 2. 
YARDIM, Gülser (2021). “17. Yüzyılın İkinci Yarısına Ait Bir Deftere Göre Muhallefattan Hazineye Aktarılan Eşyalar”, Mavi Atlas, 9(1): 147-170

Yüz elli beşinci ağaç sandık

Seraser ve kadife alaca yancik aded 6

Yüz elli altıncı sandık

Zer-duhte eğer aded 3, Kadife siyah yancık aded 1, Zer-duhte kadife yancık aded 1, Bakır kadife yancik aded 1

Yüz elli yedinci

Zer-duhte eğer aded 3, Bakır kadife yancık aded 1

$13 \mathrm{a}$

Yüz elli sekizinci sandık

Çatma yasdık aded 9, Münakkaş yatak aded 10, Kubbe seccade aded 1, Fağfûrî ibrik aded 1, Cezayir velinçesi aded 6.

Yüz elli dokuzuncu sandık

Köhne kumaş mak'ad aded 2, Köhne perde aded 1, Tatar eğeri aded 1

Yüz altmısıncı sandık

Mor kebîr çuka mak'ad aded 1, Kırmızı siyah yasdık çift aded 4, Atlas kapu perdesi aded 2, Köhne sırmalı tirkeş aded 1, Kıbrıs cibinliği aded 1, Mardin perdesi aded 1.

Yüz altmış birinci

Tüfenk silahları olur

Yüz altmış ikinci

Sim kebîrce yancık aded 2, Sırmalı eğer aded 2, Küçük 'Acem kiçesi aded 1.

Yüz altmış üçüncü kebîr ağaç sandık

Sırmalı eğer aded 1, 'Acem kiçesi aded 6, Sarı ve mavi velinçe aded 2

Yüz altmış dördüncü

Diba mak'ad aded 1, Köhne kumaş mak'ad a aded 8, Köhne kırmızı ihrâm aded 1

Yüz altmış beşinci sandık

Kırmızı Cezayir ihrâmı aded 6

Yüz altmış altıncı küçük sepet

Kırmızı Cezayir ihrâmı aded 1, Cezayir velinçesi aded 1.

Yüz altmış yedinci

Mütenevvi'a tüfenk aded 19, Çatma yasdık aded 3.

Yüz altmış sekizinci

Kutni mak'ad aded 2, Suzenî mak'ad aded 1, Kırmızı 'Acem kiçesi aded 1

$13 \mathrm{~b}$

Yüz altmış dokuzuncu sandık

Zer-duhte nihali aded 5

Yüz yetmişinci

Zer-duhte nihali aded 3

Yüz yetmiş birinci

Seraser perdeler aded 6

Yüz yetmiş ikinci

Zer-duhte nihali aded 6 
Yüz yetmiş üçüncü

Zer-duhte nihali aded 1

Seraser perde aded 4

Yüz yetmiş dördüncü

Zer-duhte nihali aded 4

Yüz yetmiş beşinci

Zer-duhte parçaları aded 9, İri iskemle zarfi aded 1, zer-duhte ocaklık aded 1, zer-duhte nihali aded 5, zer-duhte iskemle zarfı aded 1, İncülü küçük yasdık aded 4, Küçük zer-duhte yasdık aded 1, Murassa Tunus perdesi aded 1,

Yüz yetmiş altınc1

Elçiden gelen gümüş evânîler olan sandık, Sim keşkül aded 6, Sim tas ve kapak aded 6, Sim maşraba aded 4, Sim ibrik aded 4, Sim gülâbdân aded 2, Sim kapak aded 2, Sim çiçeklik aded 2, Sim küçük sandık aded 1 sim ibrik aded 2,

Yüz yetmiş yedinci,

Sim dibli sandik aded 1, Sim dibli tepsi aded 12

$14 \mathrm{a}$

Yüz yetmiş sekizinci sandık

Sahan ve kapak aded 12, Sim kebîr maşraba aded 4

Yüz yetmiş dokuzuncu

Sim kebîr maşraba aded 2, Sim kebîr şem'dân aded 2

Yüz seksaninc1

Sim kebîr buhûrdân aded 1, Sim şem'idân aded 1

Yüz seksan birinci

Sim kebîr şem'idân aded 5

Yüz seksan ikinci

Sim kebîr şem'dân aded 2, Küçük ayineli saat aded 1

Yüz seksan üçüncü

İncülü kaliçe aded 1, İncilü kebîr yasdık aded 1, Murassa atlas yasdık aded 3

Yüz seksan dördüncü

İncülü kebîr kaliçe aded 1, Altunlu mor kadife yasdık aded 1, Küçük siyah Zer-duhte yasdık aded 1, Zerbâb seccade-i pencere aded 3, Zer-duhte parça aded 5, Zer-duhte iskemle aded 1, Zer-duhte atlas basamak zarfi aded 1, Murassa atlas Tunus perdesi aded 1, Zer-duhte küçük atlas nihali aded 1

Yüz seksan beșinci

Tel tob aded 5, İri incü tob aded 2, İncülü küçük tob aded 2.

Yüz seksan altınc1

Murassa divanhane topları aded 6

$14 \mathrm{~b}$

Yüz seksan yedinci sepet

Murassa kebîr divanhane

Yüz seksan sekizinci

Kebîr Mertebânî tabak aded 10 
Yüz seksan dokuzuncu evsat, Mertebânî tabak aded 16

Yüz doksanınc1 sandık

Mertebânî kâse aded 7, Mertebânî tabak aded 4, Fağfûrî tabak aded 1.

Yüz doksan birinci sandık

Kebîr Mertebânî tabak aded 5

Yüz doksan ikinci sandık

Elçi götürdüğü hamam topları aded 6, Bayrak sim aded 6, İri hamam kolu sim aded 2, İi sim bayrak aded 15, Sim صِ aded 6 .

Yüz doksan üçüncü sand1k

Hamam ayrıkları sim aded 4, Sim şaz ve revan eşyaları olur.

Yüz doksan dördüncü sepet bozulmuştur

Yağ leğenleri olur, Ve hoş-âb tasları olur,

Yüz doksan beşinci çar köşe müdevver sandık

Sim hamam aded 1, Sim yaldızlı leğen aded 2, Sim leğen kafesi aded 2, Sim sini aded 1, Sim lengeri aded 2.

Yüz doksan altıncı siyah sandık

Sim şâtırân eşyaları olur.

Yüz doksan yedinci ağaç sandık

Sim hamam aded 1, Sim sini aded 1,Yaldızlı sini aded 1.

15 a

Yüz doksan sekizinci siyah ağaç sandık

Sim şâtırân eşyaları olur

Yüz doksan dokuzuncu ağaç sandık

Sim dolab aded 1, Sim şadırvan dilleri.

İki yüzüncü ağaç sandık

Taş doğrama sandık aded 1

İkiyüz birinci ağaç sandık

Elçi fener aded 1

İki yüz ikinci

Sedefkârî çekmece aded 2

ikiyüz üçüncü

Sedefkârî çekmece aded 1, Sim şadırvan eşyaları olur

İki yüz dödüncü sepet

Londora çuka donluk aded 15, Zer-duhte basamak aded 1.

İkiyüz beşinci derili sandik

Elçi götürdüğü iri asma saat aded 1, Çeyrekli çekmece saati maa zarfı aded 1

Zarflı çekmece saati aded 1, Küçük kulle saat aded 1.

İkiyüz altınc1 sepet

Sirmalı eğer aded 3, Sim eğer aded 1, Sadefkârî divid aded 1, Asma saat iri aded 1, Bağa zarflı saat aded 1 .

İkiyüz yedinci 
Mertebânî taak aded 2, Bülbül kafesi aded 2 bozulmuşdur.

$15 \mathrm{~b}$

Birinci deng

'Acem keçesi aded 3, Orta Selanik keçesi aded 1, Orta kubbe halı aded 1, Münakkaş seccade aded 11, Mavi velinçe aded 2, Tiftik kebe aded 1,

İkinci deng

'Acem keçesi aded 15

Üçüncü deng

Menemen seccadesi aded 22, 'Acem kiçesi aded 5, Kırmızı orta 'Acem kiçesi aded 1, Kırmızı yab acem kiçesi aded 2

Dördüncü deng aded 30

Selanik kiçesi aded 1, 'Acem kiçesi aded 6, Çuka mak'ad a aded 1, Menemen seccadesi

Beşinci deng

1

Kırmızı Cezayir velinçesi aded 1, Kırmızı Cezayir ihrâmı aded 7, Gevderi seccade aded

Altıncı denk

Orta Selanik kiçesi aded 1, Kırmızı ve mavi velinçe aded 9, Murassa çuka mak'ad aded 2, Murassa kutni mak'ad aded 2, Tüfenk kebe aded 1, Kırmızı 'Acem kiçesi köhne aded 2.

Yedinci deng

Orta Selanik kiçesi aded 13.

Sekizinci denk

Yemeni yorgan aded 7 .

Dokuzuncu denk

Tüfenk kebe aded 24, 'Acem kiçesi aded 2

Onuncu denk 3

Tüfenk kebe aded 4, Selanik keçesi aded 1, Seccade aded 1, Velinçe aded 2, Kilim aded

$16 \mathrm{a}$

On birinci deng

Musavver kebîr ibrişim halı aded 3.

On ikinci deng

Musavver kebîr ibrişim halı aded 3

On üçüncü deng

Musavver kebîr ibrişim halı aded 2, Selanik kiçesi aded 1

On dördüncü denk

Sim kebîr sini aded 2, Kiçe kırmızı astarlı perde aded 2, Tüfenk kebe aded 6, Yorgan aded 1, Cezayir velinçesi aded 2, (Sagir ve kebîr zer-duhte nihali deng beş)

$16 \mathrm{~b}$

Birinci mefraş

Yemeni yorgan aded 20

İkinci mefraş 
Yemeni yorgan aded 11

Üçüncü mefraş

Halı aded 3, Köhne kubbe seccade aded 6, Kırmızı kiçe aded 2

Dördüncü mefraş

Acem kiçesi aded 6

Beşinci mefraş

'Acem kiçesi 7

Altıncı mefraş

'Acem kiçesi aded 6

Yedinci mefraş

Tüfenk kubbe aded 4, Selanik kiçesi aded 4, 'Acem kiçesi aded 1.

Sekizinci mefraş

Selanik kiçesi aded 5

Dokuzuncu mefraş

'Acem kiçesi aded 1, Selanik keçesi aded 2.

Onuncu mefraş

Mevlüd-i şerif esvâbları olur, Yan Selanik keçesi aded 2, Kumaş mak'ad aded 5,Tüfenk kebe aded 3

\section{Sonuç}

İncelenen defterin bu çalışmada ele alınan kısımları muhallefattan gelen ve hazineye aktarılan malların dökümünü içermektedir. Dolayısıyla defterin o dönemin maddi kültürüne dair çok önemli veriler sağladığı açıtır. Defterin tarihinin 1665'li yıllara denk geldiğini biliyoruz. Dolayısıyla 17. yüzyılın ikinci yarısına ait olan bu defter sayesinde dönemin giyim unsurlarında entariler, kaftanlar, don, zıbın ve gömlekler, kürklerin dikkat çektiği anlaşılmaktadır. Ev içi döşemelerde de başat unsurların halı, kilim, makad, perde, cibinlik gibi unsurların olduğu anlaşılmaktadır, yatmak için yatak, yorgan ve yastıkların kullanılan eşyalardandır. Mutfak ve ev eşyalarında değerli madenler ve porselenlerin kullanıldığ1 anlaşılmaktadır. Çekmecelerin, saatlerin evin unsurlarından olduğu anlaşılmaktadır. Diğer yandan çeşitli madenlerden yapılan silahların, farklı özellikleri verilen tüfeklerin de varlığ1 dönemin savaş aletleriyle ilgili bilgi sağlamamıza olanak vermektedir. Bunun dışında Kâbe örtüsü parçası, kâfir bayrağı, balık dişi gibi veriler muhallefat sahiplerinin eşyaların çeşitliliğini göstermesi bakımından önemlidir.

\section{Kaynakça}

\section{Arşiv Kaynakları}

Devlet Arşivleri Başkanlığı Osmanlı Arşivi, Fon TS.MA.d. kutu/gömlek no 02321.0001 .00

\section{Araştırma Eserleri}

AKYILDIZ, Ali (1998). Mümin ve Müsrif Bir Padişah Kı̨̨ Refia Sultan, İstanbul: Tarih Vakfi Yurt Yayınları.

ARGIT ISSPŞİRLI, Betül (2014). Rabia Gülnuss Emetullab Sultan 1640-1715, İstanbul: Kitap Yayınevi.

ARSLANBOĞA Kadir (2014). Osmanl Devleti’nde Iç Hazine Harcamalar, (1649-1680), Ankara, Çanakkale Onsekiz Mart Üniversitesi Yayınları: 119. 
Hizmetlerinden.

KÖSEOĞU, Cengiz (1980). Hazৃine, İstanbul, Yap1 Kredi Bankası Kültür ve Sanat

MUMCU, Ahmet (1976). Hukuksal ve Siyasal Karar Organ Olarak Divan-ı Hümâyûn, Ankara: Ankara Üniversitesi Hukuk Fakültesi Yayınları.

OĞUZ, Gülser (2018). “Osmanlı Hanedan Mensuplarından Geriye Kalanlar” Tidsad, S. 16, ss. 350-359.

ORHONLU, Cengiz (1998). "Hazine", TDV İslam Ansiklopedisi, Test Yayını, C.17, ss. 130-133.

PARLATIR, İsmail (2003). Osmanlı Türkçesi Sözlüğü, Ankara, Yarg1 Yayınevi.

SAĞIR, Yusuf (2016), "Valide Turhan Sultan'ın Muhallefâtı", Canakkale Araștırmalar Türk Yillĭgr, Say1 20, ss. 265-328

TABAKOĞLU, Ahmet ( 1996). "Osmanlı İktisat Sistemi” Osmanl Ansiklopedisi, İstanbul C. V, ss. 9-187.

TERZİ TOZDUMAN, Arzu (2002). "Osmanlı Hazinleri”, Türkler Ansiklopedisi, C. 10, ss. 893-903.

UZUNÇARŞILI, İsmail Hakkı (1978). "Osmanlı Devleti Maliyesinin Kuruluşu ve Osmanlı Devleti İç Hazinesi”, Belleten, C. XLII, S 165,(Ayrı basım)

UZUNÇARŞILI, İsmail Hakkı (1988). Osmanlı Saray Teşkilatı, Ankara: T'TK.

YARDIM, Gülser (2019). Osmanl Devleti'nde Enderûn Hą̧inesi Gelir Defteri (1783-1803), Kayseri: Kimlik Yayınları. 